Helgoländer wiss. Meeresunters. 18, 213-231 (1968)

\title{
Untersuchungen über die Häufigkeit der Bakterien in der obersten Sedimentschicht der Deutschen Bucht in Beziehung zu den Substrateigenschaften
}

\author{
W. Hickel und W. Gunkel \\ Biologische Anstalt Helgoland, Meeresstation, Helgoland
}

\begin{abstract}
Investigations on the abundance of bacteria in the topmost sediment layer of the German Bight in relation to the substrate properties. In the German Bight (Southern North Sea) studies were conducted on the abundance of bacteria in relation to grain size distribution, organic material and water content, mainly of the topmost few millimeters of the sediment, from July, 1966, to April, 1967. Using the pour plate method, 0.005 to $120 . X$ $10^{6}$ bacteria per $\mathrm{ml}$ of wet sediment were found in the different types of sediment. In summer and autumn, the average numbers ranged from 2 to $35 \times 10^{6}$ bacteria per $\mathrm{ml}$ in sand with silt and clay, $1 \times 10^{6}$ in sand (springtime) and 60 to $100 \times 10^{6}$ in mud. Bacterial numbers appear to be 1,000 to 100,000 times higher on the sediment surface than in the water above it. In April 1967 a layer of 3 to $10 \mathrm{~cm}$ of "new" sand was found lying on the old sediment surface of the shoal regions of the German Bight - presumably a result of the heavy storms during the winter of 1966/67; this newly-added sand layer exerted pronounced effects on the abundance of both bacteria and macrofauna. The decrease of bacterial numbers in the Elbe estuary in the direction of the open sea is not continuous, because of bottom depressions with depth of more than $40 \mathrm{~m}$ where greater amounts of organic material are sedimenting. Hence, with increasing depth, bacterial numbers and amount of organic material usually increase.
\end{abstract}

\section{EINLEIT'UNG}

In flachen Nebenmeeren mit Gezeiteneinwirkung sind die Sedimentationsbedingungen besonders vielfältig und kompliziert. Der Zustrom großer Flüsse (z. B. Themse, Rhein und Elbe für die Nordsee) bringt große Sinkstoffmengen ein, die von den starken Gezeitenströmen verteilt und sortiert werden. In flachen Meeresgebieten mit Tiefen von meist nur 15 bis $30 \mathrm{~m}$ wird der Meeresboden zudem mitunter von der winderzeugten Turbulenz erreicht (Reineck 1963). Diese Faktoren bestimmen die Menge des Sestons im Wasser sowie die Sedimentationsrate und beeinflussen den Stoffaustausch an der Grenzfläche Sediment-Wasser, der hier sehr wesentlich ist. Diese Grenzfläche ist der Ort der größten Konzentration von organischer Substanz und der intensivsten mikrobiellen Abbauprozesse im Meer.

In dieser Arbeit sollen für die Deutsche Bucht einige Informationen über Höhe und Verteilung der Bakterien-Keimzahlen - besonders an der Sedimentoberfläche in Beziehung zu den unterschiedlichen Sedimentationsbedingungen und Sedimenteigen- 
schaften mitgeteilt werden, die durch Korngrößenverteilung, Wassergehalt, organische Substanz (als Glühverlust) und Redoxpotential gemessen und in bezug zur Wassertiefe und Bodentopographie verwertet werden. Die Abgrenzung des untersuchten Gebietes geht aus Abbildung 1 hervor. Zur Hydrographie der Deutschen Bucht sind für unsere Fragestellungen die Arbeiten von Lucht (1964), Goedecke (1955) und Neumann \& Meier (1964) besonders wichtig.

\section{MATERIAL UND METHODEN}

\section{Herkunft des Materials}

Im Zeitraum von Juli 1966 bis April 1967 wurden alle vorkommenden Sedimente vom reinen Schlick bis zum groben Sand in allen Wassertiefen ( 8 bis $55 \mathrm{~m}$ ) untersucht. So unterschiedliche Gebiete wie die Elbmündung (Feuerschiff „Elbe III“ bis „Elbe I"), die Tiefe Rinne südlich Helgolands, die Untiefen östlich der Düne Helgoland, die sandigen Böden nördlich, nordwestlich und südwestlich Helgolands und die Mulden (42 m) beim Feuerschiff „P 8“ (nordwestlich Helgolands) wurden dabei erfaßt. Die Abbildung 1 zeigt die Herkunft der entnommenen Sedimentproben. Im Vergleich zu den heterogenen Sedimenten zwischen Helgoland und der Elbmündung sind die ebenen, relativ gleichförmigen Sedimentflächen nördlich bis westlich von Helgoland weit weniger der Verunreinigung vom Land her ausgesetzt. Aus der Sedimentkarte von Jarke (1956) und Reineck (1963) geht die Sedimentverteilung im Gebiet hervor.

\section{Probennahme}

Da das Hauptgewicht der Untersuchungen der Sedimentoberfläche gewidmet war, mußte diese bei der Probennahme ungestört entnommen werden, was besonders bei Auflagerung von leichtem Mudd eine schwierige Aufgabe ist. Der von uns benutzte kleine Kastengreifer von REINECK (1963) erwies sich für diesen Zweck als gut geeignet. Mit Stechkästen aus rostfreiem Stahl $(10 \times 17 \times 25 \mathrm{~cm})$ wird ein Sedimentkern mit einer großen, von oben leicht zugänglichen Oberfläche gewonnen. Selbst in dünnen Schichten steht auch für Parallelproben genügend viel Sediment zur Verfügung; die verunreinigten Ränder des Kernes wurden verworfen.

Der Kastengreifer ist mit $150 \mathrm{~kg}$ für den Einsatz auf kleineren Schiffen noch handlich genug. Ist Schlick oder Schlicksand im Untergrund, bleibt Wasser über der Probe stehen; dann sind $\mathrm{pH}$ und $\mathrm{E}_{\mathrm{h}}$-Messungen am Sedimentkern an Bord möglich. Bei geringen Eindringtiefen bilden sich an den Ecken des Kastens Einsturztrichter, weswegen man - mit Ausnahme bei weichem Schlickboden - am besten mit allen 6 Bleigewichten von je $25 \mathrm{~kg}$ arbeitet, wobei der Stechkasten auch bei hartem Sand noch 10 bis $15 \mathrm{~cm}$ tief eindringt. $\mathrm{Da}$ die normalen Stechkästen aus $1 \mathrm{~mm}$ Blech beim Einsatz bei bewegter See und in Sedimenten mit Steinen und starken Muschelschalen verbiegen, wurde dann mit besserem Erfolg mit Kästen aus $4 \mathrm{~mm}$ starkem Blech gearbeitet.

Mit einem Spatel wurden 2 bis $5 \mathrm{ml}$ Sediment in $2 \mathrm{~mm}$ dicker Schicht zur Bestim- 


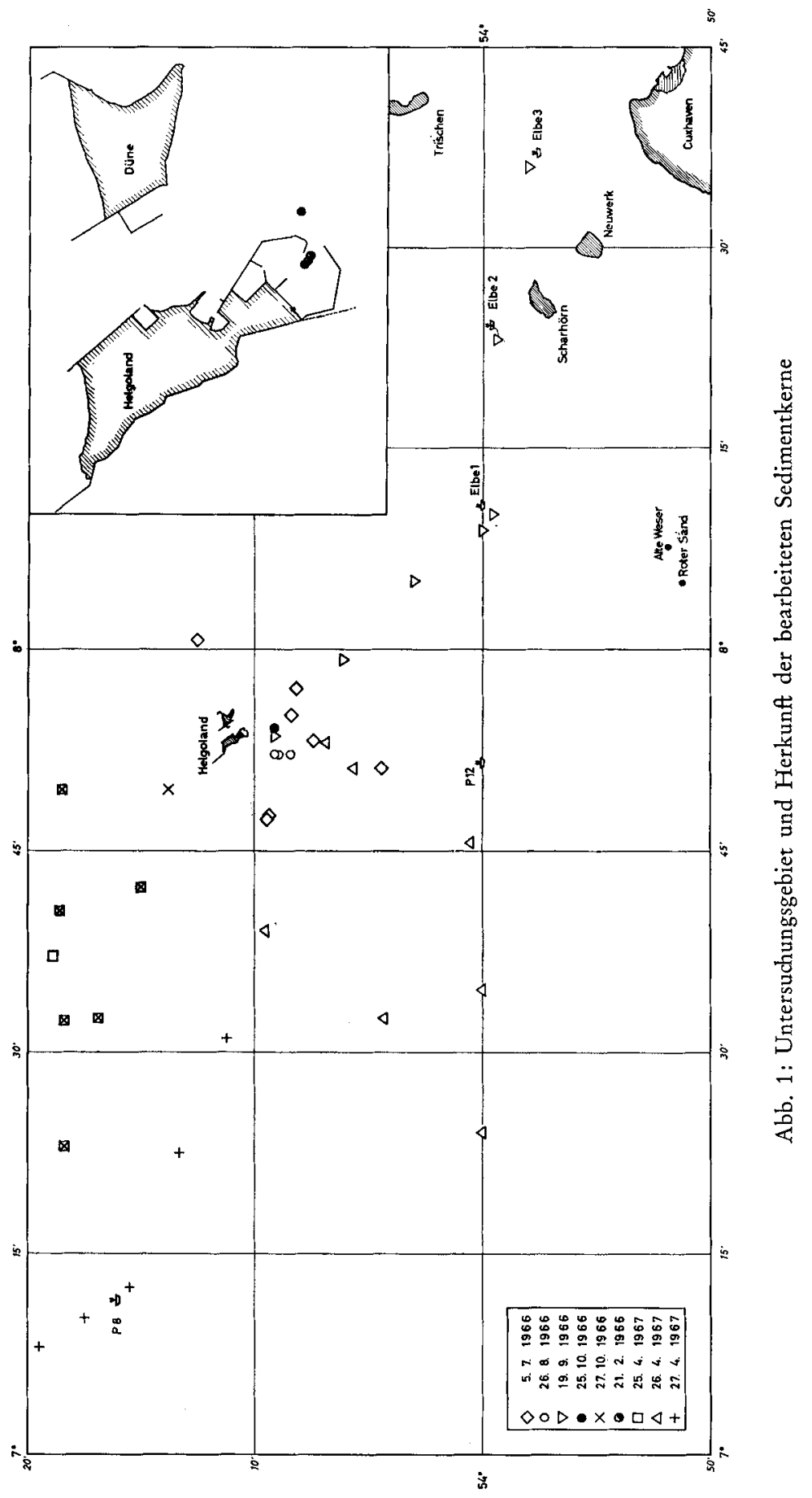


mung der Bakterienkeimzahl, eine weitere Probe für die Ermittlung von Wassergehalt und Glühverlust von der Oberfläche abgenommen. Zur Entnahme tieferer Schichten wurde der Sedimentkern aus dem Kasten entfernt.

\section{Keimzahlbestimmung}

Wenige Stunden nach der Probennahme wurde die Keimzahl der Bakterien mit der Gußplattenmethode ermittelt. Durch kühle Lagerung $\left(1\right.$ bis $\left.2^{\circ} \mathrm{C}\right)$ bis zur Aufarbeitung wurde eine Verfälschung des natürlichen Bakteriengehalts durch rasche Vermehrung weitestgehend ausgeschlossen (vgl. Zobell 1938). Der Seewasser-Nährboden 2216 E nach Oppenheimer \& Zobell (1952) fand in dem Ansatz nach Gunkel (1964a) Verwendung. 3 bis 4 Verdünnungen mit je 3 Parallelen wurden ausgeplattet.

Vor dem Anlegen der Verdünnungsreihe (bis zu 10-8) wurde die Sedimentprobe in $100 \mathrm{ml}$ sterilem Seewasser aufgeschlämmt und zwei Minuten mit einem UltraTurrax-Homogenisator (Typ TP 18/2) bei $24000 \mathrm{U} / \mathrm{min}$ behandelt (Gunkel 1964). Hierdurch werden Bakterienaggregate zerschlagen, Bakterien von Partikeln abgetrennt und das Sediment homogenisiert. Das Auszählen der Bakterienkolonien erfolgte unter einer dreifach vergrößernden Lupe und Kontrolle bei 10facher Vergrößerung nach 3-, 8-, 14- und 21tägiger Inkubation bei $18^{\circ} \mathrm{C}$. Der 21-Tage-Wert war der höchste und wurde angegeben. Die Bakterienzahlbestimmung entspricht der bei Gunkel \& Rernheimer (1968) angegebenen Methode.

\section{Physikalische und chemische Eigenschaften des Sediments}

Die Korngrößenverteilung wurde durch Naßsieben einer Sedimentprobe von 50 bis $80 \mathrm{~g}$ durch einen Siebsatz mit Maschenweiten von 1000, 500, 250, 125 und $63 \mu$, bei einigen Proben dazu noch mit $28 \mu$ ermittelt und in Prozent vom Frischgewicht angegeben. Die Bezeichnung der Korngrößen ist folgende (nach REINECK 1963): 2000 bis $630 \mu$ Grobsand, 630 bis $200 \mu$ Mittelsand, 200 bis $63 \mu$ Feinsand. Abweichend wurden die nicht weiter getrennten Korngrößen $<63 \mu$ mit dem weniger spezifischen Ausdruck "Schlick" bezeichnet, worunter hier also eine Mischung aus Silt (=Schluff, 63 bis $2 \mu$ ) und Ton $(<2 \mu) \mathrm{zu}$ verstehen ist.

Der Wassergehalt des Sediments wurde durch 18 stündiges Trocknen bei $105^{\circ} \mathrm{C}$ bestimmt, der Glühverlust der Trockensubstanz durch zweistündiges Glühen bei $550^{\circ} \mathrm{C}$ ermittelt, bei welcher Temperatur sich die organische Substanz zwar vollständig zersetzt, die Karbonate jedoch unzersetzt bleiben (UNGEMach 1961). Diese Methode kann allerdings nur relativ grobe Werte der organischen Substanz liefern.

Als Maß für den Grad der Oxydation oder Reduktion des Sediments wurden Messungen des Redoxpotentials (als $\mathrm{E}_{\mathrm{h}}$-Wert angegeben) mit einem Beckmann-pHMeter (Modell G), mit einer Spezialplatinelektrode und Bezugselektrode durchgeführt. Als Standard diente eine Lösung von $\mathrm{m} / 300 \mathrm{~K}{ }_{3} \mathrm{Fe}(\mathrm{Cn})_{6}$ und $\mathrm{m} / 300 \mathrm{~K}{ }_{4} \mathrm{Fe}(\mathrm{Cn})_{6}$ in $\mathrm{m} / 10 \mathrm{KCl}$ mit einem $\mathrm{E}_{\mathrm{h}}$-Wert von $+430 \mathrm{mV}$ nach ZoBell (1946), der ausführlich 
auf den Wert und die Durchführung von Redoxpotentialmessungen eingeht. Diese Messungen wurden an frisch an Deck geholten Proben mit überstehendem Wasser von der Sedimentoberfläche bis in 6 bis $12 \mathrm{~cm}$ Tiefe in Abständen von $1 \mathrm{~cm}$ gemacht.

\section{ERGEBNISSE}

Die Ergebnisse der Keimzahlbestimmung an der Sedimentoberfläche zusammen mit den Werten über Sedimentart, Wassergehalt, Glühverlust und Korngrößenverteilung sind aus Tabelle $1 \mathrm{zu}$ ersehen, die Werte aus tieferen Schichten derselben Sedimentkerne aus Tabelle 3. Die angegebenen Schichtdicken beziehen sich nicht exakt auf die Probe zur Korngrößenbestimmung; hierfür mußte eine ca. $1 / 2 \mathrm{~cm}$ dicke Schicht abgetragen werden, die nicht immer zum Beispiel eine dünne Muddauflagerung charakterisieren kann. Die für die Bestimmung der Bakterienzahl sorgfältig von der Oberfläche abgetragene, etwa $2 \mathrm{~mm}$ dicke Schicht kennzeichnet meist eine wasserreiche, dünne Lage frisch sedimentierter Sinkstoffe, die sich bei Sedimenten in tieferem Wasser und stromarmen Gebieten deutlich vom darunterliegenden Sand oder Schlicksand unterscheidet.

Die Bakterienzahlen an der Sedimentoberfläche, die bei der hier angewandten Methode die minimale Anzahl heterotropher, eiweißzersetzender Bakterien darstellen, schwanken zwischen den Extremen von $5 \times 10^{3}$ bis $1,2 \times 10^{8}$ pro ml Sediment. In Gebieten abseits extremer Verhältnisse ist die normale Größenordnung im Sommer und Herbst 2 bis 35 Millionen pro $\mathrm{ml}$. Auf die Fläche einer $2 \mathrm{~mm}$ dicken Sedimentoberschicht umgerechnet ergibt dies für $1 \mathrm{~cm}^{2}$ in den Extremen 0,001 bis $24 \times 10^{6}$, im Normalfall 0,4 bis $7 \times 10^{6}$ Bakterien, für $1 \mathrm{~m}^{2}$ entsprechend 0,01 bis $240 \times 10^{9}$ und 4 bis $70 \times 10^{9}$ Bakterien. Oberhalb dieser Werte liegen die Bakterienzahlen im Mudd der Stillwasserzonen und in der an organischer Substanz reichen Tiefen Rinne, weit unterhalb die von reinem Sand, besonders im Frühjahr (Tab. 2).

Im freien Wasser des gleichen Gebietes werden nach Gunkel (1963 und unpublizierte Ergebnisse) wenige hundert bis wenige tausend Bakterien pro $\mathrm{ml}$ gefunden bei Extremen von 80 und 28000 pro $\mathrm{ml}$ und einem Mittel von 1300 pro ml. Danach läßt sich abschätzen, daß in der Sedimentoberfläche 1000 - bis 100000 mal höhere Bakterienzahlen erwartet werden dürfen als im Wasser darüber.

Auf engstem Raum, in Entfernungen von wenigen Metern bis wenigen Seemeilen, finden sich entsprechend der unterschiedlichen Sedimente regelmäßig horizontale Unterschiede in der Bakterienzahl wie 1:100, während die Schwankungen in den einzelnen Wasserkörpern nur etwa $1: 10$ betragen.

Die Bakterienverteilung in tieferen Schichten des Sediments wurde nur mit wenigen Werten erfaßt. Im schwarzen Schlick des Helgoländer Vorhafens sind in $1 \mathrm{~cm}$ Tiefe noch 16 bis 60 Millionen, in $5 \mathrm{~cm}$ in der Tiefen Rinne und an der im folgenden erwähnten Grenzzone zwischen „altem“ und „neuem" Sediment ca. 5 Millionen, im anaeroben Schlicksand darunter hingegen nur noch 50000 Bakterien pro $\mathrm{ml}$ vorhanden.

Die Menge der organischen Substanz beträgt etwa 0,3 bis $12 \%$ der Trockensubstanz und der Wassergehalt des Frischsediments 13 bis $65 \%$ entsprechend der Höhe der organischen Substanz. Ein Wassergehalt von 50 bis $65 \%$ bei ca. $10 \%$ organi- 


Datum Untersuchtes Gebiet $\underset{\mathrm{m}}{\text { Tiefe }} \underset{\text { tionen }}{\text { Sta- }}$ Art des vorgefundenen Sedimentes

5. 7. 1966 Südlich von Tiefer

Rinne Helgoland

Südlicher Rand von

Tiefer Rinne

Loreley-Bank, östl.

Helgoland-Düne

Südlicher Rand von

Tiefer Rinne

Mitte von Tiefer

Rinne

26. 8. 1966 Mitte von Tiefer Rinne

Nördlicher Rand von Tiefer Rinne

Nördlicher Rand von Tiefer Rinne

19. 9. 1966 Leuchttonne LT 8 bei FS Elbe III Feuerschiff Elbe II

Südlich FS Elbe I Westlich FS Elbe I

Tonne $\mathrm{H} 1$

Tonne $\mathrm{H} 2$

Leuchttonne

Helgoland

25. 10. 1966 Nördlicher Rand der Tiefen Rinne Südreede Helgoland Helgol. Vorhafen (nahe Ausfahrt)

\begin{tabular}{|c|c|c|}
\hline 41 & 1 & sandiger Schlick, Ofl. Mudd \\
\hline 42 & 2 & sandiger Schlick, Tierröhren, \\
\hline 40 & 3 & brauner Sand mit wenig Schlick \\
\hline 14 & 4 & reiner Grobsand \\
\hline 44 & 5 & feinster, reiner Schlick \\
\hline 55 & 6 & Sand mit viel Schlick und Schill \\
\hline 52 & 1 & Sand mit viel Schlick und Schill \\
\hline 40 & 2 & $\begin{array}{l}\text { dichte Bestände von Bryozoen } \\
\text { (Flustra) mit viel Schlick da- } \\
\text { zwischen } \\
\text { Mulden zwischen Flustra- } \\
\text { Beständen }\end{array}$ \\
\hline 46 & 3 & $\begin{array}{l}3 \text { bis } 4 \mathrm{~cm} \text { dicke Schicht mit } \\
\text { Flustra-Kolonien, dazwischen viel } \\
\text { Schlick } \\
\text { Mulden zwischen Flustra- } \\
\text { Beständen }\end{array}$ \\
\hline 12 & 1 & $\begin{array}{l}\text { Feinsand mit etwas Schlick, Ofl. } \\
\text { dünne Muddschicht (Stillwasser!) }\end{array}$ \\
\hline 20 & 2 & $\begin{array}{l}\text { Feinsand mit etwas Schlick, kein } \\
\text { Mudd (starker Strom) }\end{array}$ \\
\hline 22 & 3 & Schlick mit etwas Feinsand \\
\hline 24 & 4 & $\begin{array}{l}\text { schwarzer Schlick (verklappter } \\
\text { Klärschlamm?), Of. Mudd, dar- } \\
\text { unter braune, aerobe Schicht mit } \\
\text { Pectinaria }\end{array}$ \\
\hline 24 & 5 & $\begin{array}{l}\text { schwarzer, weicher Schlick (ver- } \\
\text { klappter Klärschlamm?), Ofl. } \\
5 \text { bis } 10 \mathrm{~mm} \text { lockerer Mudd }\end{array}$ \\
\hline 28 & 6 & Schlick mit Feinsand \\
\hline 53 & 7 & $\begin{array}{l}\text { sandiger Schlick mit viel } \\
\text { Bruchschill }\end{array}$ \\
\hline 41 & 1 & $\begin{array}{l}\text { sandiger Schlick mit viel } \\
\text { Bruchschill }\end{array}$ \\
\hline $\begin{array}{r}10 \\
8\end{array}$ & $\begin{array}{l}2 \\
3\end{array}$ & $\begin{array}{l}\text { reiner, mittelsandiger Feinsand } \\
\text { schwarzer Schlick, Ofl. Muddschicht }\end{array}$ \\
\hline
\end{tabular}

1 Keine Bestimmungen am 5. 7. und 26. 8.1966

20 bis $3 \mathrm{~cm}$ Schicht

33 bis $5 \mathrm{~cm}$ Schicht 


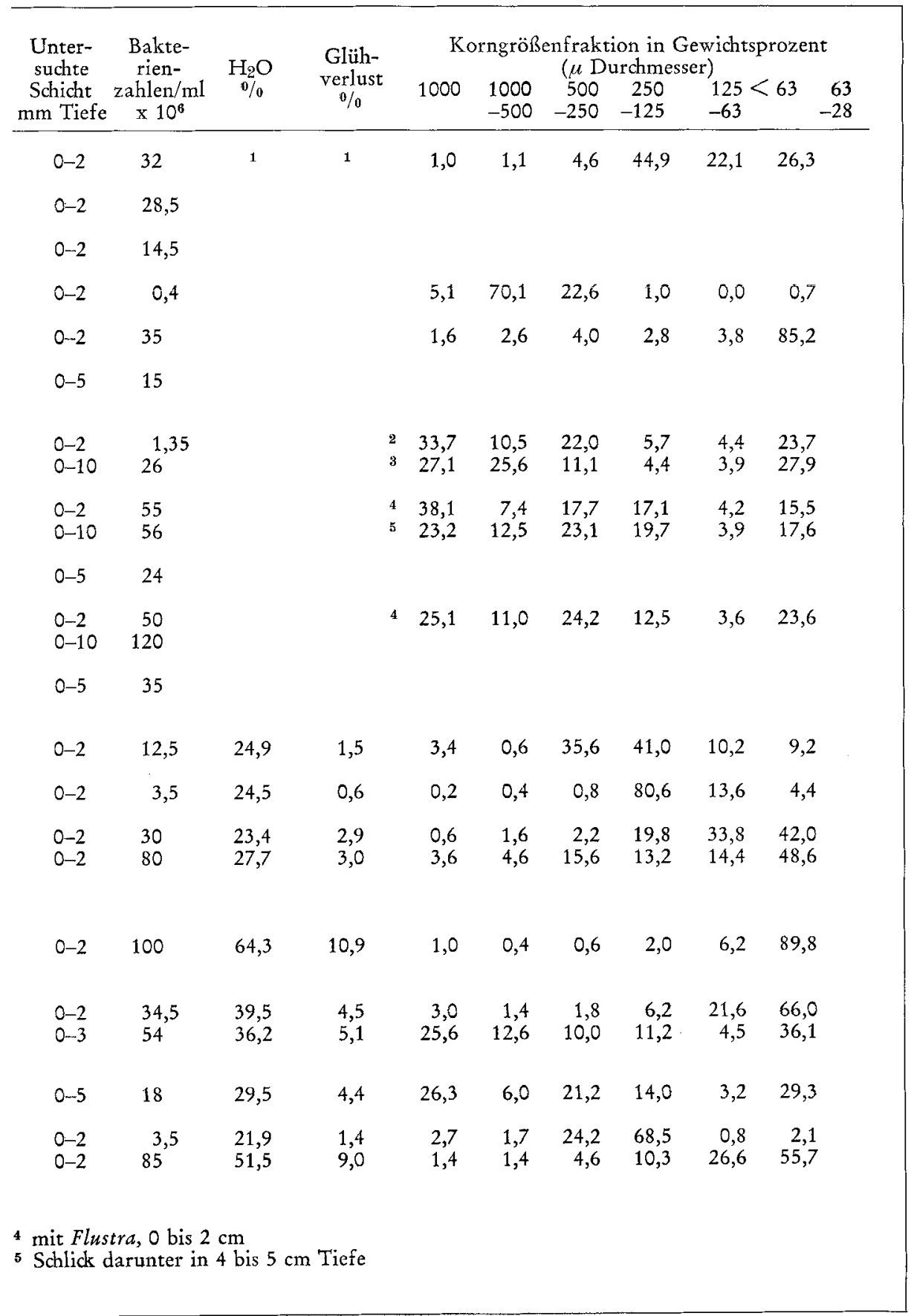


Fortsetzung Tabelle 1

Datum Untersuchtes Gebiet $\underset{\mathrm{m}}{\text { Tiefe }} \underset{\text { tionen }}{\text { Sta- Art des vorgefundenen Sedimentes }}$

27. 10. 1966 Ost-West-Schnitt nördlich Helgoland

21. 2. 1967 Helgol. Vorhafen (nahe Ausfahrt)

25. 4. 1967 Ost-West-Schnitt nördlich Helgoland

26. 4. 1967 Südwestlich und
27. 4. 1967 Schnitt Feuerschiff

P 8 - Helgoland

\section{südlich Helgolands}

\begin{tabular}{|c|c|c|c|c|}
\hline Datum & Untersuchtes Gebiet & $\begin{array}{l}\text { Tiefe } \\
\mathrm{m}\end{array}$ & $\underset{\text { Sta- }}{\text { Stonen }}$ & Art des vorgefundenen Sedimentes \\
\hline 27. 10.1966 & $\begin{array}{l}\text { Ost-West-Schnitt } \\
\text { nördlich Helgoland }\end{array}$ & $\begin{array}{l}22 \\
29 \\
38 \\
42 \\
40 \\
38 \\
24\end{array}$ & $\begin{array}{l}1 \\
2 \\
3 \\
3 \\
4 \\
5 \\
6 \\
7\end{array}$ & $\begin{array}{l}\text { feinsandiger Mittelsand mit viel } \\
\text { Lanice und anderen Tieren } \\
\text { grobsandiger Mittelsand, wenige } \\
\text { Tiere } \\
\text { feinsandiger Mittelsand mit etwas } \\
\text { Schlick, wenige Tiere } \\
\text { mittelsandiger Feinsand, Ofl. Mudd } \\
\text { mittelsandiger Feinsand } \\
\text { mittelsandiger Feinsand } \\
\text { Feinsand mit Schlick }\end{array}$ \\
\hline 21. 2. 1967 & $\begin{array}{l}\text { Helgol. Vorhafen } \\
\text { (nahe Ausfahrt) }\end{array}$ & $\begin{array}{l}8 \\
8\end{array}$ & $\begin{array}{l}1 \\
2\end{array}$ & $\begin{array}{l}\text { feinsandiger schwarzer Schlick, } \\
\text { Ofl. Muddschicht } \\
\text { feinsandiger schwarzer Schlick, } \\
\text { Ofl. Muddschicht }\end{array}$ \\
\hline 25. 4. 1967 & $\begin{array}{l}\text { Ost-West-Schnitt } \\
\text { nördlich Helgoland }\end{array}$ & $\begin{array}{l}22 \\
29 \\
26 \\
38 \\
42 \\
40 \\
38\end{array}$ & $\begin{array}{l}1 \\
2 \\
3 \\
4 \\
\\
5 \\
6 \\
7\end{array}$ & $\begin{array}{l}\text { Mittelsand, wenig Tiere } \\
\text { (Echinocardium) } \\
\text { grobsandiger Mittelsand, kaum } \\
\text { Tiere } \\
\text { feinsandiger Mittelsand, mehr } \\
\text { Tiere (tiefer Schlicksand) } \\
\text { mittelsandiger Feinsand } 5 \mathrm{~cm}, \\
\text { tiefer Schlicksand } \\
\text { mittelsandiger Feinsand mit Schlick } \\
\text { mittelsandiger Feinsand mit Schlick } \\
\text { Schlick mit Feinsand }\end{array}$ \\
\hline 26. 4. 1967 & $\begin{array}{l}\text { Südwestlich und } \\
\text { südlich Helgolands }\end{array}$ & $\begin{array}{l}36 \\
36 \\
30 \\
34 \\
36 \\
42 \\
41\end{array}$ & $\begin{array}{l}1 \\
2 \\
3 \\
4 \\
5 \\
6 \\
6 \\
7\end{array}$ & $\begin{array}{l}\text { dunkler, mittelsandiger Feinsand } \\
\text { mit Schlick } \\
\text { dunkler Feinsand mit viel Schlick } \\
\text { Feinsand } 6 \text { bis } 7 \mathrm{~cm} \text { über } \\
\text { Schlicksand } \\
\text { feinsandiger Schlick, Ofl. Mudd } \\
\text { Feinsand } 3 \text { bis } 5 \mathrm{~cm} \text { mit Tier- } \\
\text { röhren über Schlicksand } \\
\text { feinsandiger Schlick } 2 \mathrm{~cm} \text { über } \\
\text { Schlick, Ofl. mit Mudd } \\
\text { feinsandiger Mittelsand mit Schlick } \\
\text { über Schlick, Ofl. mit Mudd }\end{array}$ \\
\hline 27. 4. 1967 & $\begin{array}{l}\text { Schnitt Feuerschiff } \\
\text { P } 8-\text { Helgoland }\end{array}$ & $\begin{array}{l}37 \\
38 \\
36\end{array}$ & $\begin{array}{l}3 \\
4 \\
5\end{array}$ & $\begin{array}{l}\text { Feinsand } 4 \text { bis } 5 \mathrm{~cm} \text { über schwar- } \\
\text { zem Schlicksand, abgestorbene } \\
\text { Lanice an der Grenze } \\
\text { Feinsand } 4 \text { bis } 5 \mathrm{~cm} \text { über schwar- } \\
\text { zem Schlicksand, abgestorbene } \\
\text { Lanice an der Grenze } \\
\text { Feinsand } 3 \text { bis } 5 \mathrm{~cm} \text { über Schlick- } \\
\text { sand, Of. Mudd } \\
\text { Feinsand } 3 \text { bis } 5 \mathrm{~cm} \text { über Schlick- } \\
\text { sand, Ofl. Mudd } \\
\text { Feinsand } 3 \text { bis } 5 \mathrm{~cm} \text { über Schlick- } \\
\text { sand, Ofl. Mudd }\end{array}$ \\
\hline
\end{tabular}


Fortsetzung Tabelle 1

\begin{tabular}{|c|c|c|c|c|c|c|c|c|c|c|}
\hline $\begin{array}{l}\text { Unter- } \\
\text { suchte } \\
\text { Schicht } \\
\text { mm Tiefe }\end{array}$ & $\begin{array}{l}\text { Bakte- } \\
\text { rien- } \\
\text { zahlen/ml } \\
\quad \times 10^{6}\end{array}$ & $\underset{\% \%}{\mathrm{H}_{2} \mathrm{O}}$ & $\begin{array}{l}\text { Glüh- } \\
\text { verlust } \\
\% \%\end{array}$ & 1000 & $\begin{array}{r}1000 \\
-500 \\
\end{array}$ & $\begin{array}{c}\text { enfrakt } \\
(\mu \mathrm{D} t \\
500 \\
-250 \\
\end{array}$ & $\begin{array}{l}\text { ion in } \\
\text { urchmes } \\
250 \\
-125\end{array}$ & $\begin{array}{l}\text { ewichts } \\
\text { er) } \\
125 \\
-63\end{array}$ & $\begin{array}{l}\text { prozent } \\
6 \\
63\end{array}$ & $\begin{array}{r}63 \\
-28 \\
\end{array}$ \\
\hline $0-2$ & 2 & 19,6 & 3,0 & 1,0 & 1,0 & 73,6 & 22,6 & 0,8 & 1,0 & \\
\hline $0-2$ & 7 & 16,8 & 7,1 & 1,0 & 32,0 & 48,6 & 18,0 & 0,4 & 0,0 & \\
\hline $0-2$ & 6,4 & 20,4 & 0,7 & 1,4 & 1,4 & 53,6 & 39,2 & 1,2 & 2,8 & 0,4 \\
\hline $\begin{array}{l}0-2 \\
0-2 \\
0-2 \\
0-2\end{array}$ & $\begin{array}{l}12,5 \\
10,5 \\
19 \\
35\end{array}$ & $\begin{array}{l}19,5 \\
19,7 \\
24,6 \\
31,1\end{array}$ & $\begin{array}{l}1,5 \\
1,8 \\
2,8 \\
4,9\end{array}$ & $\begin{array}{l}2,2 \\
2,2 \\
2,8 \\
2,4\end{array}$ & $\begin{array}{l}1,2 \\
2,0 \\
1,0 \\
1,2\end{array}$ & $\begin{array}{r}16,4 \\
36,0 \\
14,2 \\
1,8\end{array}$ & $\begin{array}{l}53,4 \\
43,6 \\
55,4 \\
37,0\end{array}$ & $\begin{array}{l}23,0 \\
11,6 \\
13,2 \\
37,4\end{array}$ & $\begin{array}{r}3,8 \\
2,0 \\
9,4 \\
10,6\end{array}$ & $\begin{array}{l}2,6 \\
4,0 \\
9,6\end{array}$ \\
\hline $0-2$ & 75 & 49,5 & 7,7 & 2,8 & 1,5 & 4,8 & 24,8 & 17,4 & 48,9 & \\
\hline $0-2$ & 50 & 65,8 & 12,5 & 3,0 & 2,0 & 6,3 & 9,7 & 15,2 & 41,9 & 21,9 \\
\hline $0-2$ & 0,285 & 16,8 & 0,31 & 0,6 & 10,6 & 66,0 & 22,0 & 0,8 & 0,0 & \\
\hline $0-2$ & 0,015 & 13,3 & 0,23 & 1,1 & 29,0 & 55,0 & 13,0 & 1,9 & 0,0 & \\
\hline $0-2$ & 0,135 & 17,4 & 0,32 & 1,4 & 3,8 & 34,2 & 58,2 & 1,2 & 1,2 & \\
\hline $0-2$ & 0,005 & 18,1 & 0,51 & 1,1 & 1,9 & 27,5 & 66,3 & 2,1 & 1,1 & \\
\hline $\begin{array}{l}0-2 \\
0-2 \\
0-2\end{array}$ & $\begin{array}{l}0,05 \\
0,05 \\
0,6\end{array}$ & $\begin{array}{l}23,2 \\
22,3 \\
30,7\end{array}$ & $\begin{array}{l}1,30 \\
0,96 \\
2,40\end{array}$ & $\begin{array}{l}1,9 \\
0,3 \\
2,1\end{array}$ & $\begin{array}{l}3,5 \\
1,3 \\
0,6\end{array}$ & $\begin{array}{l}23,9 \\
15,2 \\
10,0\end{array}$ & $\begin{array}{l}42,8 \\
64,1 \\
44,5\end{array}$ & $\begin{array}{r}16,4 \\
9,6 \\
14,1\end{array}$ & $\begin{array}{r}11,5 \\
9,5 \\
28,7\end{array}$ & \\
\hline $0-2$ & 0,05 & 21,6 & 0,72 & 0,6 & 1,6 & 34,9 & 50,3 & 5,6 & 7,0 & \\
\hline $\begin{array}{l}0-2 \\
0-2\end{array}$ & $\begin{array}{l}0,15 \\
3,5\end{array}$ & $\begin{array}{l}27,8 \\
22,7\end{array}$ & $\begin{array}{l}2,10 \\
1,10\end{array}$ & $\begin{array}{l}0,6 \\
0,3\end{array}$ & $\begin{array}{l}0,7 \\
0,4\end{array}$ & $\begin{array}{l}1,7 \\
1,6\end{array}$ & $\begin{array}{l}29,9 \\
86,0\end{array}$ & $\begin{array}{r}46,9 \\
7,0\end{array}$ & $\begin{array}{r}20,2 \\
4,7\end{array}$ & \\
\hline $\begin{array}{l}0-2 \\
0-2\end{array}$ & $13^{0,05}$ & $\begin{array}{l}36,5 \\
35,4\end{array}$ & $\begin{array}{l}3,30 \\
3,20\end{array}$ & $\begin{array}{l}0,7 \\
0,4\end{array}$ & $\begin{array}{l}0,9 \\
0,5\end{array}$ & $\begin{array}{l}2,2 \\
1,1\end{array}$ & $\begin{array}{l}32,4 \\
30,7\end{array}$ & $\begin{array}{l}24,4 \\
46,0\end{array}$ & $\begin{array}{l}39,4 \\
21,3\end{array}$ & \\
\hline $0-2$ & 12,5 & 41,9 & 4,00 & 0,8 & 3,1 & 7,5 & 21,2 & 19,3 & 48,1 & \\
\hline $0-2$ & 6,95 & 29,5 & 2,30 & 4,0 & 13,7 & 40,3 & 15,4 & 5,6 & 21,0 & \\
\hline $0-2$ & 0,2 & 26,5 & 2,00 & 0,5 & 0,3 & 0,2 & 14,0 & 68,9 & 16,1 & \\
\hline $0-2$ & 8,5 & 26,5 & 2,00 & 0,8 & 0,6 & 0,8 & 15,9 & 69,4 & 12,5 & \\
\hline $0-2$ & 0,05 & 28,3 & 2,20 & 0,5 & 0,5 & 0,8 & 14,4 & 67,2 & 16,6 & \\
\hline $0-2$ & 6,25 & 28,1 & 2,00 & 0,5 & 0,5 & 0,8 & 18,2 & 62,0 & 18,0 & \\
\hline $0-2$ & 0,3 & 25,5 & 1,80 & 1,2 & 0,6 & 6,0 & 38,0 & 42,2 & 12,0 & \\
\hline
\end{tabular}


Tabelle 2

Charakteristische Bakterienzahlen für die Oberfläche der verschiedenen Sedimente der Deutschen Bucht. (Bakterienzahlen mit der Gußplattenmethode in $10^{6}$ pro $\mathrm{ml}$ Frischsediment und pro $1 \mathrm{~cm}^{2}$ einer $2 \mathrm{~mm}$ dicken Oberflächenschicht)

\begin{tabular}{|lcc|}
\hline Art des Sediments & $106 / \mathrm{ml}$ & $10^{6} / \mathrm{cm}^{2}$ \\
\hline $\begin{array}{l}\text { Reiner, durch Wasserbewegung gut sortierter Sand von } \\
\text { Flachs und Stellen mit starker Strömung }\end{array}$ & $0,4-7$ & $0,08-1,4$ \\
„Neuer Sand“, durch Stürme umgelagert, im Frühjahr & $0,01-0,6$ & $0,002-0,12$ \\
Sand mit Schlickbeimengung & $10-19$ & $2-3,6$ \\
$\begin{array}{l}\text { Sand mit viel Schlick, Schlick mit Sand, Oberfläche oft } \\
\text { mit Mudd, aus größeren Wassertiefen }\end{array}$ & $28-35$ & $5,6-7$ \\
desgl. im Frühjahr (Mulden bei FS „P 8“) & $3,5-13$ & $0,7-2,6$ \\
Sandiger Schlick mit viel Bruchschill und organischen & $15-54$ & $3-10,8$ \\
Resten aus der Tiefen Rinne südlich Helgolands & & 7 \\
Reiner Schlick (Ton und Silt) & 35 & $4,8-24$ \\
Schlick und Mudd zwischen Bryozoen & $24-120$ & $16-20$ \\
(Flustra-)Beständen & & $10-17$ \\
Mudd auf Schlick, vor der Elbmündung & $80-100$ & \\
Mudd auf Schlick, Helgoländer Vorhafen & $50-85$ & \\
\hline
\end{tabular}

scher Substanz ist typisch für reinen Mudd, 25 bis $35 \%$ Wasser bei 2 bis $5 \%$ organischer Substanz für Schlicksand, etwa 15 bis $25 \%$ Wasser bei 0,5 bis $1,4 \%$ organischer Substanz für Sand, wenn nicht viele Tiere zur Anreicherung organischer Stoffe beitragen. Die Bakterienzahlen für diese drei Sedimentarten sind aus Tabelle 2 zu ersehen. Ahnliche Werte für organische Substanz wurden auch in entsprechenden Sedimenten der Ostsee von Zeitzschel (1964) gefunden.

Zum Verständnis der beobachteten jahreszeitlichen Unterschiede im Bakteriengehalt der Sedimentoberfläche um mehrere Größenordnungen sind die Sedimentkerne vom April 1967 besonders aufschlußreich. In dem zu dieser Zeit untersuchten Gebiet nordwestlich, westlich und südwestlich Helgolands fand sich nämlich fast überall eine 3 bis $10 \mathrm{~cm}$ dicke Schicht reinen, hellen Sandes auf dunklem, offensichtlich älterem Sediment. Dies konnte im Herbst des Vorjahres noch nicht beobachtet werden, so daß die Vermutung naheliegt, daß während der sehr starken Stürme im Spätwinter 1966/67 Sand aufgewirbelt und umgelagert wurde. Dafür spricht auch, daß an vielen Stellen eine scharfe Grenze zwischen hellem Sand und dunklem, anaerobem Schlicksand zu erkennen war. Hier, an der vermuteten alten Sedimentoberfläche, fanden sich in einigen Kernen zahlreiche Röhren sedentärer Polychaeten (Lanice conchilega), die offensichtlich übersandet worden waren. Eine sehr viel höhere Bakterienzahl zeigte hier eine Anreicherung von organischen Stoffen durch abgestorbene Tiere an.

Sollte diese Sedimentumlagerung bei starken Stürmen die Regel sein, muß dies eine entscheidende Bedeutung für Tierbesiedlung, mikrobielle Aktivität und den ganzen Chemismus im Sediment sowie den Boden-Wasser-Austausch haben.

Es ist offensichtlich, daß jahreszeitliche Unterschiede zum Beispiel der Bakterien- 


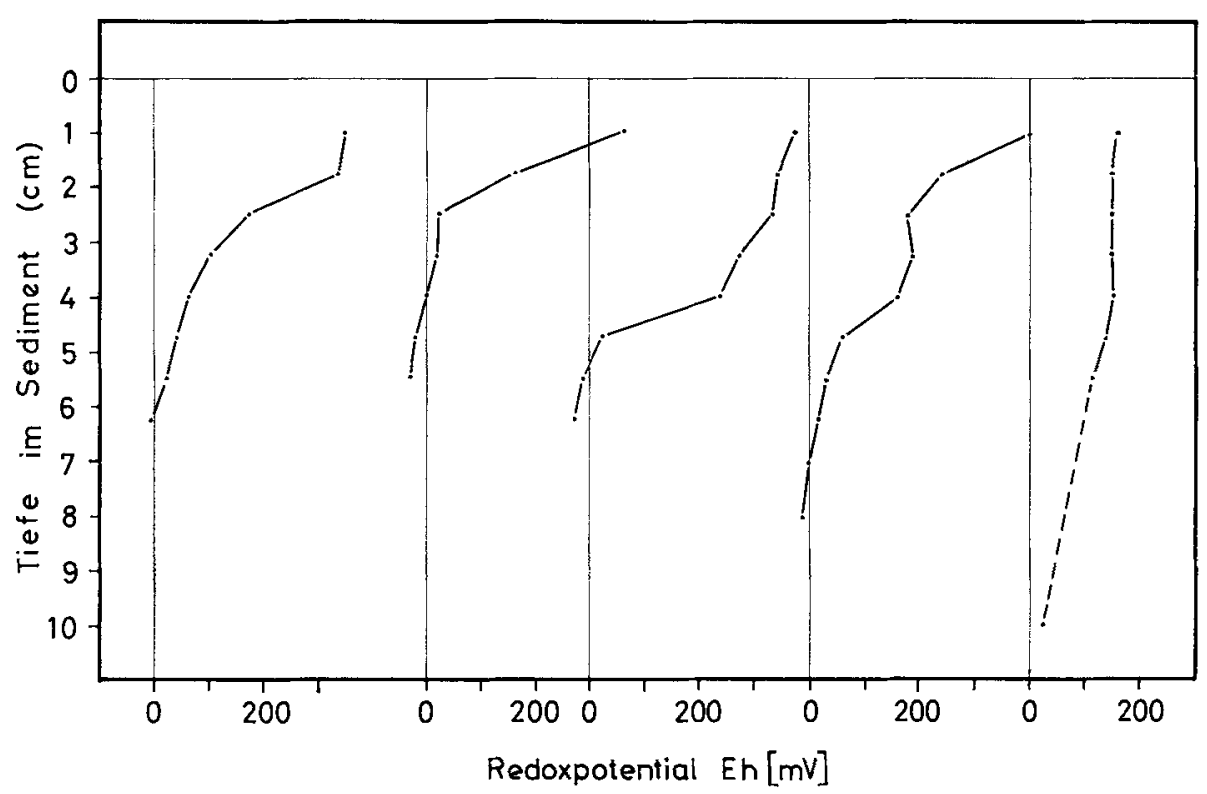

Abb. 2: Vertikale Meßreihen des Redoxpotentials im Sediment nordwestlich und südwestlich Helgolands. Typische Beispiele vom April 1967

häufigkeit und der organischen Substanz aus Beobachtungen allein der Sedimentoberfläche nicht abgeleitet werden sollten. Vielmehr sind die Schichtungsverhältnisse als Indikator für die wechselnden Sedimentationsbedingungen bis in mindestens 15 bis $20 \mathrm{~cm}$ Tiefe mit $\mathrm{zu}$ verwerten, da sonst wichtige Umlagerungserscheinungen unerkannt bleiben können.

Auf dem im Frühjahr 1967 wiederholten Ost-West-Schnitt nordwestlich von Helgoland konnten an gleichen Stationen gegenüber den Herbst-Werten 200 - bis $1000 \mathrm{mal}$ geringere Bakterienzahlen festgestellt werden (Tab. 4). Zehnfach weniger organische Substanz fand sich bis in etwa $30 \mathrm{~m}$, nicht aber in größerer Wassertiefe (um $40 \mathrm{~m}$ ), wo auch keine wesentliche Überschichtung mit Sand augenscheinlich war. Eine eindeutige Veränderung der Korngrößenverteilung war hingegen nicht ausgeprägt. Die relativ weit geringere Anzahl der Bakterien pro Einheit organischer Substanz im ,neuen “Sand kann andeuten, daß die Bakterienentwicklung hier im Frühjahr noch nicht dem Angebot an organischen Stoffen folgen konnte.

Die Schichtung des Sediments wurde auch durch Messungen des Redoxpotentials untersucht. Der Verlauf der Vertikalkurven des $\mathrm{E}_{\mathrm{h}}$-Wertes gibt Aufschlüsse über die vom Gehalt an organischer Substanz abhängigen Aktivität der Mikroorganismen, die den Reduktionsgrad im Sediment bestimmt.

Es ließ sich so eine gut oxydierte Oberschicht von nur 1 bis $2,5 \mathrm{~cm}$ Dicke und dann ein rascher Abfall des $E_{h}$-Wertes erkennen (Abb. 2). Bei einigen Sedimentkernen fehlten solche Gradienten bis in $10 \mathrm{~cm}$ Tiefe, bei mehreren waren Zwischenschichten mit erhöhtem $\mathrm{E}_{\mathrm{h}}$-Wert erkennbar. 


\begin{tabular}{|c|c|c|c|c|}
\hline Datum & Untersuchtes Gebiet & $\begin{array}{l}\text { Tiefe } \\
\mathrm{m}\end{array}$ & $\begin{array}{c}\text { Sta- } \\
\text { tionen }\end{array}$ & Art des vorgefundenen Sedimentes \\
\hline 26. 8. 1966 & $\begin{array}{l}\text { Nördlicher Rand } \\
\text { der Tiefen Rinne }\end{array}$ & 46 & 3 & $\begin{array}{l}\text { Schicht } 3 \text { bis } 4 \mathrm{~cm} \text { mit Tierkolonien } \\
\text { abgetragen, darunter anaerober } \\
\text { Schlick mit Sand }\end{array}$ \\
\hline 25. 10.1966 & $\begin{array}{l}\text { Helgol. Vorhafen } \\
\text { (nahe Ausfahrt) }\end{array}$ & 8 & 3 & $\begin{array}{l}\text { schwarzer, anaerober, feinsandiger } \\
\text { Schlick }\end{array}$ \\
\hline 21. 2. 1967 & $\begin{array}{l}\text { Helgol. Vorhafen } \\
\text { (nahe Ausfahrt) }\end{array}$ & 8 & 1 & $\begin{array}{l}\text { schwarzer, feinsandiger Schlick un- } \\
\text { ter dünner, aerober Schicht (brau- } \\
\text { ner Mudd): Grenzzone } \\
8 \mathrm{~mm} \text { abgetragen: schwarzer, an- } \\
\text { aerober, feinsandiger Schlick mit } \\
\text { bräunlichen Streifen } \\
\text { schwarzer, feinsandiger Schlick } \\
\text { schwarzer, feinsandiger Schlick un- } \\
\text { ter dünner, aerober Schicht (brau- } \\
\text { ner Mudd): Grenzzone } \\
8 \mathrm{~mm} \text { abgetragen: schwarzer, an- } \\
\text { aerober, feinsandiger Schlick mit } \\
\text { bräunlichen Streifen } \\
\text { schwarzer, feinsandiger Schlick }\end{array}$ \\
\hline \multirow[t]{2}{*}{ 26. 4. 1967} & $\begin{array}{l}\text { südwestlich } \\
\text { Helgolands }\end{array}$ & 36 & 2 & dunkler Schlicksand \\
\hline & & 42 & 6 & $\begin{array}{l}\text { Grenzzone Feinsand mit Tieren/ } \\
\text { sandiger Schlick } \\
\text { feinsandiger Schlick (altes } \\
\text { Sediment) } \\
\text { feinsandiger Schlick unter dünner } \\
\text { Sandschicht }\end{array}$ \\
\hline 27. 4. 1967 & $\begin{array}{l}\text { Schnitt FS P } 8 \text { - } \\
\text { Helgoland }\end{array}$ & 38 & 2 & $\begin{array}{l}\text { Feinsand } 3 \text { bis } 5 \mathrm{~cm} \text { über Schlick- } \\
\text { sand, viele Tiere in der Ober- } \\
\text { schicht, abgestorbene Lanice in der } \\
\text { Grenzzone zum anaeroben Sedi- } \\
\text { ment: Grenzzone } \\
\text { anaerober Schlicksand } \\
\text { wie vorige Probe; Grenzzone: } \\
\text { anaerober Schlicksand }\end{array}$ \\
\hline
\end{tabular}

Die Messung jahreszeitlich bedingter Unterschiede des Gehalts an Bakterien und organischer Substanz (etwa durch Absinken von totem Plankton) läßt sich also bestenfalls an den gegen starke Wasserbewegungen geschützten Bodenflächen erkennen, wozu aber unser Material aus dem Helgoländer Vorhafen und den Mulden nordwestlich Helgolands nicht ausreicht. Der Tiefen Rinne südlich Helgolands kommt insofern eine besondere Stellung zu, als ihr Boden fortwährend von den Grundschleppnetzen der Kutterfischerei aufgewühlt wird, die hier das ganze Jahr über besonders intensiv ist, so daß kaum ein Bodenstück ungestört bleiben dürfte. Damit entfällt eine Beurteilung identischer Sedimentoberflächen. 


\begin{tabular}{|c|c|c|c|c|c|c|c|c|c|c|}
\hline $\begin{array}{l}\text { Unter- } \\
\text { suchte } \\
\text { Schicht } \\
\text { cm 'T'iefe }\end{array}$ & $\begin{array}{l}\text { Bakte- } \\
\text { rien } \\
\text { zahlen/ml } \\
\times 10^{\theta}\end{array}$ & $\underset{0 \%}{\mathrm{H}_{2} \mathrm{O}}$ & $\begin{array}{c}\text { Glüh- } \\
\text { ver- } \\
\text { lust } \\
0 \%\end{array}$ & 1000 & $\begin{array}{l}1000 \\
-500\end{array}$ & $\begin{array}{c}\text { nfrakt } \\
(\mu \mathrm{D} \\
500 \\
-250\end{array}$ & $\begin{array}{l}\text { Ion in } C \\
\text { urchmes } \\
250 \\
-125\end{array}$ & $\begin{array}{l}\text { wichtst } \\
125< \\
-63\end{array}$ & $\begin{array}{l}\text { brozen } \\
<63 \\
\end{array}$ & $\begin{array}{r}63 \\
-28\end{array}$ \\
\hline $5-6$ & 4,6 & - & - & $\begin{array}{l}23,2 \\
12,1\end{array}$ & $\begin{array}{l}12,5 \\
19,9\end{array}$ & $\begin{array}{l}23,1 \\
26,7\end{array}$ & $\begin{array}{l}19,7 \\
14,7\end{array}$ & $\begin{array}{l}3,9 \\
2,6\end{array}$ & $\begin{array}{l}17,6 \\
24,0\end{array}$ & \\
\hline $0,3-0,5$ & 60 & 46,6 & 9,0 & 2,5 & 1,0 & 2,5 & 11,0 & 19,8 & 63,2 & \\
\hline $0,3-0,4$ & 56 & 47,9 & 7,2 & 2,8 & 1,5 & 4,6 & 24,8 & 17,4 & 48,9 & \\
\hline $0,8-1,0$ & 48 & 40,1 & 5,9 & 2,1 & 1,0 & 6,3 & 21,9 & 19,5 & 49,2 & \\
\hline $\begin{array}{c}10-11 \\
0,3-0,4\end{array}$ & 20,5 & $\begin{array}{l}44,8 \\
62,0\end{array}$ & $\begin{array}{r}7,6 \\
11,3\end{array}$ & $\begin{array}{l}4,2 \\
3,0\end{array}$ & $\begin{array}{l}3,7 \\
2,0\end{array}$ & $\begin{array}{l}4,7 \\
6,3\end{array}$ & $\begin{array}{r}16,8 \\
9,7\end{array}$ & $\begin{array}{l}15,9 \\
15,2\end{array}$ & $\begin{array}{l}44,7 \\
41,9\end{array}$ & 21,9 \\
\hline $0,8-1,0$ & 16,5 & 54,6 & 9,9 & 1,5 & 1,8 & 4,9 & 11,2 & 13,2 & 67,4 & \\
\hline $10-11$ & & 54,2 & 11,0 & 0,3 & 0,9 & 1,2 & 3,9 & 11,0 & 69,4 & 13,3 \\
\hline $5-6$ & & 24,2 & 2,3 & 0,2 & 0,4 & 2,0 & 44,3 & 38,8 & 14,3 & \\
\hline $4-5$ & & 29,2 & 2,5 & 0,5 & 0,2 & 0,9 & 19,3 & 53,5 & 25,6 & \\
\hline $10-11$ & & 23,3 & 1,9 & 0,1 & 0,3 & 1,1 & 21,6 & 51,9 & 25,0 & \\
\hline $5-6$ & & 30,8 & 2,9 & 0,2 & 4,6 & 16,3 & 18,4 & 18,9 & 41,6 & \\
\hline $4-5$ & 5,5 & 23,8 & 2,3 & 0,4 & 0,5 & 0,5 & 12,6 & 66,2 & 19,8 & \\
\hline $\begin{array}{l}8-9 \\
3-4 \\
8-9\end{array}$ & $\begin{array}{l}0,05 \\
5,5\end{array}$ & $\begin{array}{l}24,2 \\
23,2 \\
23,3\end{array}$ & $\begin{array}{l}2,0 \\
2,2 \\
2,1\end{array}$ & $\begin{array}{l}0,9 \\
0,6 \\
0,5\end{array}$ & $\begin{array}{l}0,2 \\
0,4 \\
0,2\end{array}$ & $\begin{array}{l}0,2 \\
0,3 \\
0,3\end{array}$ & $\begin{array}{l}11,1 \\
12,8 \\
15,1\end{array}$ & $\begin{array}{l}66,7 \\
71,2 \\
69,0\end{array}$ & $\begin{array}{l}20,9 \\
14,7 \\
14,9\end{array}$ & \\
\hline
\end{tabular}

Die hier analysierten Oberflächenschichten von $2 \mathrm{~mm}$ Dicke stellen oft eine Muddauflagerung dar, die nicht immer typisch für das Sediment darunter sein muß, das ja das Ergebnis der Sedimentation längerer Zeiträume ist. So wird auch in Gebieten mit starker Strömung und daher rein sandigem Sediment (Elbmündung bei Feuerschiff „Elbe II“, Helgoland-Reede) in den Minuten der Stillwasserzeit aus dem schwebstoffreichen Wasser Mudd auf den Sand sedimentieren und beim Einsetzen des Stromes wieder aufgewirbelt werden. Nach LUCHT (1964) sind nach dem oft heftig einsetzenden Strom Trübungswolken sichtbar und meßbar. Bei Vergleichen der Sedimentoberflächen wäre in der Nordsee also die Tidenphase zu berücksichtigen. 


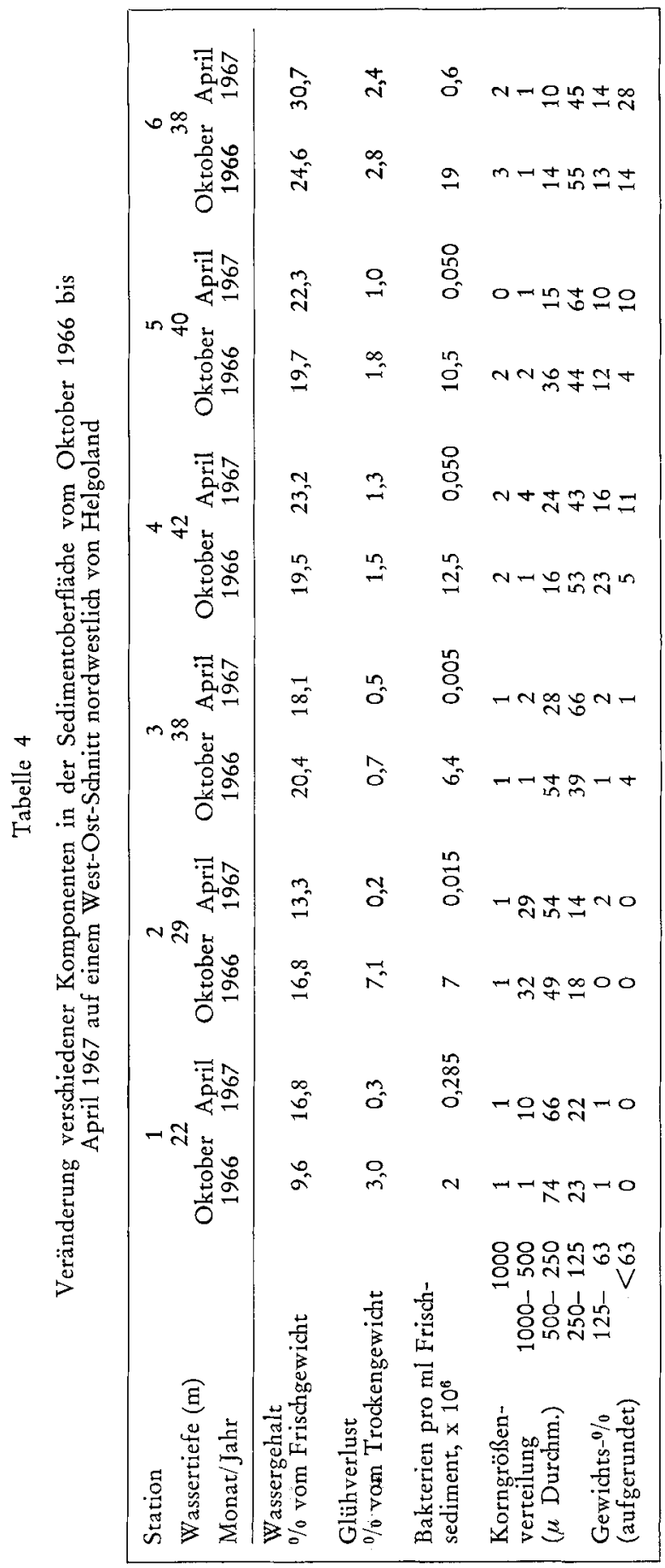




\section{DISKUSSION}

Zwei Gradienten der Verteilung von Bakterienzahl und organischer Substanz sind in der Deutschen Bucht zu erwarten: Einmal eine Abnahme organischer Sinkstoffe, von denen ein großer Teil als allochthones Material durch die Flüsse eingebracht wird (vgl. KöRNER 1955), und damit auch eine Abnahme der Bakterien von den Flußmündungen zur offenen See hin. Zum anderen eine Abnahme der Korngröße mit zunehmender Wassertiefe und daher Landferne und damit eine Zunahme organischer Sinkstoffe.

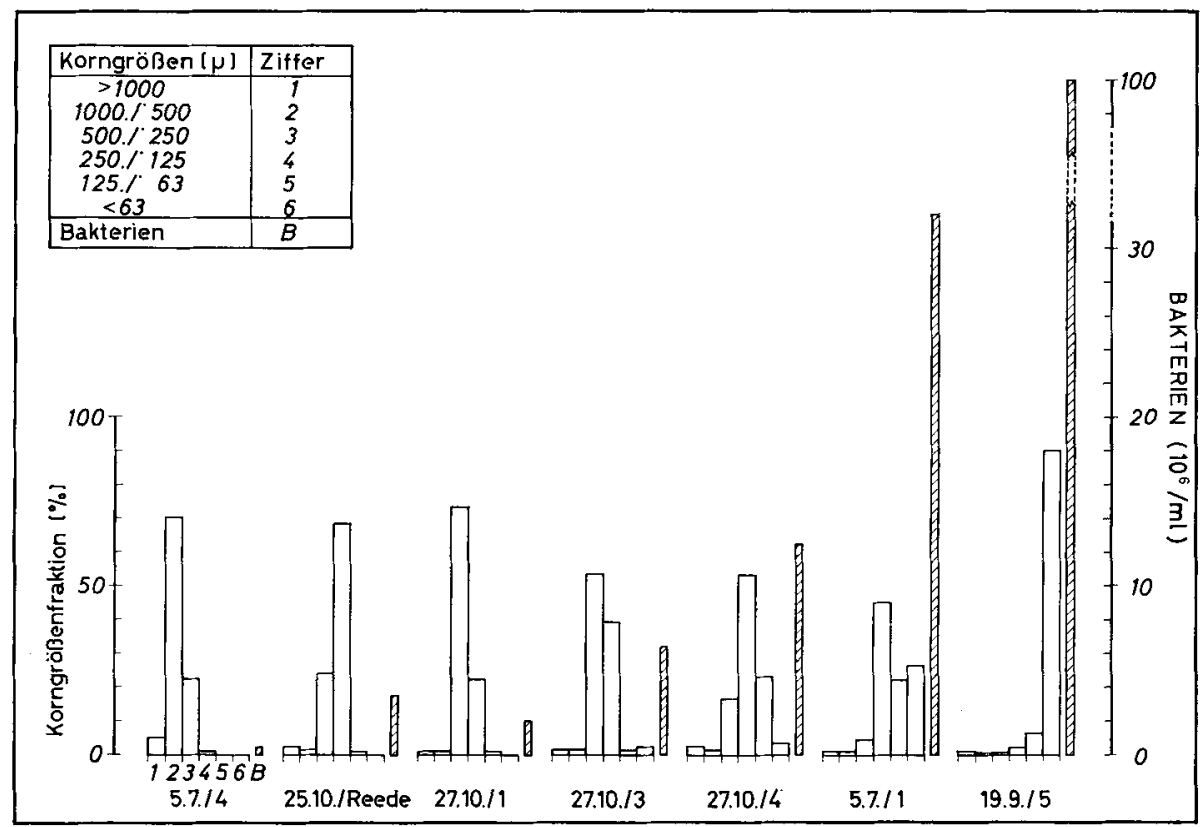

Abb. 3: Korngrößenverteilung und Bakterienzahl in der Oberfläche verschiedener Sedimente. Zunahme der Keimzahl mit steigendem Anteil feinster Korngrößen

Der erste Effekt, der etwa auf einem Schnitt Elbmündung - Feuerschiff P 8 erkennbar sein müßte, wird überlagert durch die Wirkung starker Gezeitenströme im Elbmündungsgebiet und durch die wechselnde Topographie des Meeresbodens, besonders der Tiefen Rinne (50 bis $60 \mathrm{~m}$ ). Auch scheinen künstliche Verunreinigungen, wie die Verklappung großer Mengen von ausgefaultem Klärschlamm der Hamburger Kläranlage Köhlbrandhöł $1 \mathrm{sm}$ NW Tonne "Großvogelsand W“ (15 m Tiefe) und (bei schlechtem Wetter) $7 \mathrm{sm}$ westlich Feuerschiff „Elbe I“ (24 m Tiefe) im Elbmündungsgebiet erheblich zu stören (Tab. 1, 19. 9. 1966, Stationen 4 und 5). Wie aus Tabelle 1 hervorgeht und wie auch WEYLAND (1967) bemerkt, findet man daher keine klaren Gradienten etwa der Bakterienzahlen seewärts ausgebildet.

Dagegen ist der zweite Gradient deutlich ausgeprägt: Auf den Ost-West-Schnitten nordwestlich von Helgoland, wo der Boden langsam nach seewärts abfällt, zeigt sich 
mit zunehmender Wassertiefe eine deutliche Abnahme der Sandkorngrößen und noch besser eine Zunahme der organischen Substanz und der Bakterienzahlen (Tab. 4). Mit der Zunahme der Kornfraktion mit dem kleinsten Durchmesser $(<63 \mu)$ und der Abnahme des Sortierungsgrades nimmt bei allen untersuchten Kernen rasch die Bakterienzahl zu, wie an typischen Beispielen aus Proben vom Sommer und Herbst 1966 (Abb. 3) zu ersehen ist. Zobell (1938) bringt nach Trask (1932) eine Aufstellung, die den Zusammenhang zwischen Partikelgröße, Bakterienzahl, Wassergehalt und Stickstoffgehalt im Sediment verdeutlicht und die ähnliches zeigt.

Zwei Ursachen, die sich überlagern, sind für die Zunahme der Bakterienzahlen bei steigendem Anteil feinster Korngrößen anzunehmen. Einmal ist die Größe der sedimentierten Partikel ein Ausdruck der hydrographischen Gegebenheiten, der Wassertiefe und des Bodenreliefs, die alle einen Einfluß auf die turbulente Wasserbewegung haben, welche neben der Größe und dem Gewicht der Teilchen die Sedimentationsrate bestimmt. Dort, wo sich die kleinen, mineralischen Partikel $(<63 \mu \phi$, also Silt und Ton) absetzen, sinken auch die zwar voluminösen, doch spezifisch leichten Flocken des organischen Detritus ab, die den Mudd bilden. Diese haben wiederum große Bakterienzahlen zur Folge, was also nicht auf die gewichtsmäßig völlig dominierenden mineralischen Partikel zurückgehen muß, die in diesem Falle nur Indikatoren für die günstigen Sedimentationsbedingungen des leichten Detritus wären.

Zum anderen aber nimmt die Oberfläche, die den Bakterien zur Anheftung dient, mit abnehmender Korngröße zu. Außerdem ist es bekannt, daß mineralische Partikel (besonders Ton) in starkem Maße gelöste organische Verbindungen adsorbieren (DEGENS 1965, OpPENHEIMER 1960). Diese Tatsache ist besonders dann für das Bakterienwachstum entscheidend, wenn der Gehalt an gelöster organischer Substanz im umgebenden Wasser den für Bakterien ausnutzbaren Schwellenwert nicht erreicht und Bakterien infolgedessen erst nach Anreicherung der organischen Stoffe an Partikeln wachsen können, was der Normalfall im freien, oligotrophen Meerwasser ist. Wenn aber - wie im Porenwasser des Sediments möglich - eine hohe Konzentration an gelösten organischen Substanzen vorliegt, kommt der Partikeloberfläche nicht mehr die gleiche Bedeutung zu wie etwa im freien Wasser. Um diese Frage zu klären, müßten mikroskopische Untersuchungen an unbehandelten Sandkörnern, Anlegen von Gußplatten ohne und mit Vorbehandlung des Sediments sowie Bakterien- und Nährstoffbestimmungen des Porenwassers durchgeführt werden.

Vergleichbare Angaben über Bakterienhäufigkeit im Sediment unseres Untersuchungsgebietes sind bei WEYLAND (1967) zu finden, der aber - allerdings auf nur einer Fahrt - etwa zehnmal weniger Bakterien fand als den Werten aus Tabelle 1 entspricht $\left(0,006\right.$ bis $6,5 \times 10^{6} \mathrm{im}$ Juli). Dies wird einmal an der Probennahme gelegen haben, da er nicht die Abspülung der Oberfläche seiner mit dem Van-Veen-Greifer genommenen Proben ausschließen konnte. Zum anderen aber homogenisierte er die Sedimentprobe nur durch Schütteln.

Für die Brauchbarkeit der Behandlung des Sediments mit dem Ultra-Turrax, mit der Gunkel (1964) bis 100mal höhere Bakterienzahlen gegenüber den Werten im unbehandelten Sediment bekam, spricht auch, daß die meisten in den Gußplatten sichtbaren Sandkörner steril waren und die Bakterienkolonien von ihnen entfernt wuchsen. Auch wurden, wenn beim Anlegen der Verdünnungsreihe $1 \mathrm{ml}$ Suspension vergleichs- 
weise einmal mit viel, zum anderen mit zehnmal weniger Sand angesaugt wurde, recht ähnliche Bakterienzahlen gefunden, was das gleiche aussagt.

Erst eine gute und gleichartige Homogenisierung erlaubt den Vergleich der Bakterienzahlen verschiedenartiger Sedimente, da die Bakterien ja in ganz unterschiedlichen Aggregaten vorliegen können. Interessant sind hierzu die Befunde von TsERnoGLOU (1962), der die Korngrößenverteilung von mit einem Mixer behandelten und vergleichsweise unbehandeltem Sediment mit dem Coulter Counter maß und dabei große Unterschiede feststellte. Es kommt dabei u. a. ein Zusammenbacken feinster Partikel durch Abscheidungen von Organismen (Bakterien?) in Frage.

Der Aussagewert der Bakterienzahl mit der Gußplattenmethode wird dadurch begrenzt, daß hier die Fähigkeit der Bakterien bewertet wird, auf dem erwähnten Nährboden mit Pepton und Hefeextrakt zu sichtbaren Kolonien heranzuwachsen und damit die vitalsten Eiweißzersetzer begünstigt sind. Selbstverständlich werden so nicht alle Bakterien erfaßt, wohl aber untereinander gut vergleichbare Werte erzielt. $\mathrm{Da}$ im Rahmen produktionsbiologischer Aspekte die Sedimentoberfläche als der Ort entscheidender Remineralisationsprozesse gesehen werden muß, spielt hier in diesem Zusammenhang die physiologische Leistung der Bakterien, organische Substanz, besonders Eiweißkörper, abzubauen, die entscheidende Rolle; ist es doch die Aktivität der eiweißzersetzenden Bakterien, die zum begrenzenden Faktor des turnovers der organisch gebundenen Ionen (Stickstoff und Phosphor) im Stoffkreislauf des Meeres werden kann. Ohne die bakterielle Remineralisation dieser Ionen würde der Vorgang der Primärproduktion im Meer bald zum Erliegen kommen.

Eine Gesamtkeimzahl kann man nur mit einer Direktzählmethode erwarten. Sie ist dann mindestens 10 - bis 100 mal höher als die Keimzahl mit indirekten Kulturmethoden (ZoBELl 1954). Selbst wenn es gelänge, eine Direktzählung weniger zeitaufwendig zu gestalten und zudem mit Sicherheit die besonders kleinen Meeresbakterien von unbelebten Partikeln zu unterscheiden - wovon man noch weit entfernt ist - kann man nur eine Aussage über den standing crop und damit zum Beispiel den Nahrungswert der Bakterien-Biomasse gewinnen.

Berechnet man diese aus den hier vorgelegten Bakterienzahlen mit dem von ZoBELL (1963) angegebenen Wert von $2 \times 10^{-13} \mathrm{~g}$ Biomasse (Feuchtgewicht) für ein Bakterium, so ergibt sich für die Bakterienbiomasse in der Sedimentoberfläche der Helgoländer Bucht $10^{-6}$ bis $2,4 \times 10^{-2} \mathrm{mg}$ pro $\mathrm{ml}$ Sediment in den Extremwerten und $4 \times 10^{-4}$ bis $7 \times 10^{-3} \mathrm{mg}$ pro $\mathrm{ml}$ für die "normalen" Anzahlen von 2 bis $35 \times 10^{6}$ Bakterien pro $\mathrm{ml}$. Pro $1 \mathrm{~cm}^{2}$ Fläche einer $2 \mathrm{~mm}$ dicken Sedimentoberschicht fänden sich dann 0,002 bis $48 \times 10^{-4} \mathrm{mg}$ Bakterienbiomasse für die extremen Bakterienzahlen von 0,005 bis 120 mal $10^{6}$ pro $\mathrm{ml}$ und 0,8 bis $14 \times 10^{-4}$ für die normalen Bakterienzahlen von 2 bis 35 mal $10^{6}$ pro ml. Auf $1 \mathrm{~m}^{2}$ berechnet wären das 0,002 bis $48 \mathrm{mg}$ bzw. 0,8 bis $14 \mathrm{mg}$ Bakterienbiomasse.

Zobell (1963) gibt eine Zusammenstellung der Biomasse verschiedener Organismengruppen pro $\mathrm{m}^{2}$ in den obersten $0,5 \mathrm{~cm}$ des Meeressediments nach Daten von MARE (1942), wonach die Bakterienbiomasse zwar etwa der von Diatomeen im Boden entspricht und höher ist als die von Protozoen, jedoch vom Meiobenthos 20 mal und vom Makrobenthos $100 \mathrm{mal}$ übertroffen wird. Damit scheint es, daß die Bakterienbiomasse als standing crop wohl nur in Ausnahmefällen überhaupt eine Bedeutung hat. Jedoch 
bewirkt die hohe Teilungsrate der Bakterien eine sehr wesentliche Produktion an organischer Substanz, die gegenüber der Produktion langsamwüchsiger Makro- und Meioorganismen schon eher ins Gewicht fallen dürfte.

Statt des häufig verwendeten Bezugs der Bakterienzahlen auf das SedimentTrockengewicht wurde hier das Volumen des Frischsediments mit dem natürlichen Porenwasser gewählt, das als Gefüge von Sandkörnern und Interstitialräumen dem Lebensraum der Bakterien besser Rechnung trägt. Ein Bezug auf Gewicht wäre dann besser, wenn alle Bakterien an Partikeln säßen und alle Sedimentpartikel gleich schwer wären, was im ersten Fall wenig, im zweiten nicht wahrscheinlich ist.

\section{ZUSAMMENFASSUNG}

1. Von Juli 1966 bis April 1967 wurden in der Deutschen Bucht Sedimentkerne mit dem Kastengreifer in allen vorkommenden Sedimentarten genommen, um besonders an der Sedimentoberfläche als der Grenzfläche Boden-Wasser die Häufigkeit der Bakterien in Beziehung zu Korngrößenverteilung, organischer Substanz (Glühverlust) und Wassergehalt zu untersuchen.

2. Bakterienzahlen zwischen 0,005 bis $120 \times 10^{6}$ pro $\mathrm{ml}$ Sediment wurden mit der Gußplattenmethode gefunden. Im Sommer und Herbst war die normale Größenordnung 2 bis $35 \times 10^{6}$ für Schlicksand, im Frühjahr $1 \times 10^{6}$ für Sand, 60 bis 100 mal $10^{6}$ für Mudd (Tab. 3). Berechnet auf $1 \mathrm{~m}^{2}$ Sedimentoberfläche von $2 \mathrm{~mm}$ Dicke ergeben sich 0,01 bis $240 \times 10^{9}$ Bakterien in den Extremen und 4 bis $70 \times 10^{9}$ Bakterien im Normalfall.

3. An der Sedimentoberfläche lassen sich demnach 1000 - bis 100000 mal höhere Bakterienzahlen pro $\mathrm{ml}$ feststellen als im Wasser darüber, bei horizontalen Unterschieden von $1: 100$.

4. Im April 1967 wurde fast überall nördlich, nordwestlich und südwestlich Helgolands eine neu aufgelagerte Sandschicht von 3 bis $10 \mathrm{~cm}$ Dicke festgestellt, was auf die Wirkung der Orkane im Spätwinter 1966/67 zurückgehen und große Bedeutung für die Biologie des Sediments haben dürtte. Jahreszeitliche Unterschiede an identischen Sedimentflächen konnten daher nicht eindeutig erkannt werden. Färbung und Redoxpotentialmessungen ließen an den meisten Sedimentkernen eine starke Schichtung im Oxydationsgrad erkennen.

5. Eine Abnahme der Bakterienzahlen im Sediment von der Elbmündung nach See hin läßt sich nicht als Regel beobachten, wohl aber deren Ansteigen mit der Wassertiefe und allgemein der Abnahme der Wasserbewegungen am Boden und damit der $\mathrm{Zu}$ nahme des Anteils der feinsten sedimentierten Partikel (Silt und Ton). So steigen auf einem Ost-West-Schnitt senkrecht zur nordfriesischen Küste Bakterienzahlen und organische Substanz mit der Wassertiefe an, wobei die Korngröße des Sediments abnimmt.

6. In der Sedimentoberfläche der Deutschen Bucht errechnet sich die Biomasse der Bakterien mit 0,002 bis $48 \mathrm{mg}$ pro $1 \mathrm{~m}^{2}$ einer $2 \mathrm{~mm}$ dicken Oberflächenschicht für die Extremwerte und mit 0,8 bis $14 \mathrm{mg}$ pro $\mathrm{m}^{2}$ für die normalerweise vorkommenden Bakterienzahlen. 
Herrn H.-H. Trekel und Herrn K. Treutner sagen wir Dank für ihre gewisserhafte Mitarbeit. Fernerhin sei an dieser Stelle der Deutschen Forschungsgemeinschaft, durch deren Unterstïtzung diese Untersuchungen ermöglicht wurden, gedankt.

\section{ZITIERTE LITERATUR}

Degens, E. T., 1965. Geochemistry of sediments. A brief survey. Prentice-Hall, London 342 pp. Goedecke, E., 1955. Uber die Intensität der Temperatur-, Salzgehalts- und Dichteschichtung in der Deutschen Bucht. Dt. bydrogr. Z. 8, 15-28.

Gunkel, W., 1963. Daten zur Bakterienverteilung in der Nordsee. Veröff. Inst. Meeresforsch. Bremerh., Sonderbd 3, 80-89.

- 1964a. Einwirkungen des kalten. Winters $1962 / 63$ auf die Bakterienpopulation vor Helgoland. Helgoländer wiss. Meeresunters. 10, 246-256.

- 1964b. Die Verwendung des Ultra-Turrax zur Aufteilung von Bakterienaggregaten in marinen Proben. Helgoländer wiss. Meeresunters. 11, 287-295.

- \& Rheinheimer, G., 1968. Bakterien. In: Schlieper, C. (Hrsg.), Methoden der meeresbiologischen Forschung. Fischer, Jena, 142-157.

JARкE, J., 1956. Eine neue Bodenkarte der südlichen Nordsee. (Der Boden der südlichen Nordsee. 1. Beitrag.) Dt. bydrogr. Z. 9, 1-9.

Körner, B., 1955. Die Sinkstoffe der Küstengewässer. Ein Öberblick über den Stand der Forschung. Küste 4, 5-51.

Lucht, F., 1964. Hydrographie des Elbe-Ästuars. Arch. Hydrobiol. Suppl. 29, 1-96

Neumann, H. \& Meder, C., 1964. Die Oberflächenströme in der Deutschen Bucht. Dt. bydrogr. Z. 17, $1-40$.

Oppenhermer, C. H., 1960. Bacterial activity in sediments of shallow marine bays. Geochim. cosmochim. Acta 19, 244-260.

- \& ZoBell, C. E., 1952. The growth and viability of sixty-three species of marine bacteria as influenced by hydrostatic pressure. J. mar. Res, 11, 10-18.

Reineck, H. E., 1963. Sedimentgefüge im Bereich der südlichen Nordsee. Abh. senckenb. naturforsch. Ges. 505, 1-138.

- 1963. Der Kastengreifer. Die Entwicklung eines Gerätes zur Entnahme ungestörter, orientierter Grundproben vom Meeresboden. Natur Mus. 93, 102-108.

Trask, P. D., 1932. Origin and environment of source sediments of petroleum. Gulf Publ. Co., Houston, Texas.

Tsernoglov, D., 1962. Contribution of the study, structure and microbiology of marine and freshwater sediments. MA Thesis, Dalhousie Univ., Halifax, N.S., Can.

Ungemach, H., 1960. Sedimentchemismus und seine Beziehungen zum Stoffhaushalt in 40 europäischen Seen. Nat. math. Diss. Kiel, 420 pp.

WEYLAND, H., 1967. Beitrag zur quantitativen Verteilung mariner und "terrestrischer" Bakterien im Wasser und in Sedimenten der Deutschen Bucht. Helgoländer wiss. Meeresunters. $15,226-242$.

ZeitzsChel, B., 1965. Zur Sedimentation von Seston, eine produktionsbiologische Untersuchung von Sinkstoffen und Sedimenten der westlichen und mittleren Ostsee. Kieler Meeresforsch. 11, 55-80.

Zobell, C. E., 1938. Studies on the bacterial flora of marine bottom sediments. J. sedim. Petrol. 8, 10-18.

- 1946. Studies on redox potential of marine sediments. Bull. Am. Ass. Petrol. Geol. 30, 477-513.

- 1954. The occurrence of bacteria in the deep sea and their significance for animal life. In: On the distribution and origin of the deep sea bottom fauna. Coll. Un. int. Sci. biol. 16, 20-26.

- 1963. Domain of the marine microbiologist. In: Oppenheimer, C. H. (Ed.): Symposium on marine microbiology. C. C. Thomas, Springfield, Ill., 3-24. 